\title{
Psychosocial status of childhood cancer survivors who develop one or more secondary malignancies ${ }^{\star}$
}

\author{
Roman Korenjak ${ }^{1}$, Mojca Čižek Sajko ${ }^{2}$, Berta Jereb ${ }^{3}$
}

${ }^{1}$ Outpatient psychological department Railway Health Center Ljubljana, Slovenia

${ }^{2}$ Institute for Biostatistics and Medical Informatics, Faculty of Medicine Ljubljana, Slovenia

${ }^{3}$ Institute of Oncology, University Medical Centre Ljubljana, Slovenia

Corresponding author: Mojca Čižek Sajko Institute for Biostatistics and Medical Informatics Faculty of Medicine University of Ljubljana Vrazov trg 2 1000 Ljubljana

Slovenia mojca.cizek.sajko@gmail.com Tel.: + 38615437770

Fax: + 38615437771

Received: 22 November 2011 Accepted: 10 September 2011

${ }^{*}$ Presented at the $3^{\text {rd }}$ European Symposium on Late Complications after Childhood Cancer, Amsterdam, Netherlands, September 29 to 30, 2011

Copyright (C) 2011 by

Academy of Sciences and Arts of Bosnia and Herzegovina. E-mail for permission to publish: amabih@anubih.ba
Objective. Childhood cancer survivors can develop physical, emotional and psychosocial adversities, a secondary malignancy (SM) being one of the most serious among them. The aim of our research was to study whether the development of SM was related to the psychosocial functioning of survivors, especially whether any psychic trauma from the first experience would be aggravated by SM. Patients and methods. Seventy - five childhood cancer survivors with SM were matched with 75 survivors who did not develop SM, by sex, age, living enviroment, diagnosis, year of diagnosis and treatment of the first malignancy. They were compared regarding education, employment, marital status and, in the 35 women, childbirth data. Seventeen childhood survivors with an SM had had psychological evaluations at diagnosis of both their first and secondary cancers; the results of the two were compared. Results. There were no differences in the schooling, education, social, marital status or birth specifics between survivors with SM and their controls, nor were there marked differences in measures of social or psychological status. Conclusions. The socioeconomic status of these 75 subjects was not found to be related to the development of SM. Psychological evaluations showed no marked differences between those conducted after the first and the secondary malignancies.

Key words: Childhood, Secondary malignancy, Psychological evaluation, Socioeconomic status.

\section{Introduction}

Approximately two thirds of childhood cancer survivors will display one or more delayed sequelae of treatment $(1,2)$. Permanent worries about health, problems with schooling, employment and complicated relations in the family may negatively influence their quality of life (QOL) (3). There are, however, some investigators who report that childhood cancer survivors have the same QOL as their peers: they find as many married, have the same number of children and undergo no more divorces when 
compared to the general population $(4,5)$. It is not clear either, whether depression and suicide rates among childhood cancer survivors are higher $(6,7)$. There are, moreover, inconsistencies in QOL reports suggesting to some that survivors may be biased in their responses to questionnaires (8-10). There is also a lack of comparability across studies due to wide variations in study designs. More information regarding these issues is needed (11). We therefore report the psychosocial and psychological functioning of childhood cancer survivors who developed SM as one of the important determinants influencing their quality of life.

Somatic late sequelae as well as cognitive and psychosocial functioning have been extensively analysed and reported $(12,13)$. Cognitive, emotional, behavioral and psychosocial problems are the most common. Disturbances of concentration, attention span and memory could be the result of any one of many causes and their interactions with individual idiosyncracies including age at diagnosis and treatment administered $(14,15)$. Among the somatic adversities, SM is one of the most serious. Development of SM in the survivor might also awaken painful memories of the first malignant tumor and all it entailed. We did not find any reports comparing psychosocial functioning of childhood cancer survivors who developed SM with those who did not.

The aim of this study was to find out whether the development of SM was related to the psychosocial functioning of survivors, and if any negative sequelae after the first diagnosis became even stronger and deeper after the diagnosis of SM. We compared the socioeconomic status of 75 childhood cancer survivors who had SM and of 75 matched survivors who did not. We further compared the findings of psychological testing of 17 childhood cancer survivors who were assessed both after the first cancer was found and after SM. Moreover, their find- ings were compared with 17 survivors who did not develop SM.

\section{Patients and methods}

\section{Patients}

In Slovenia, obligatory registration of all cancer patients became established in 1950 with the advent of the Cancer Registry of Slovenia. Treatment of children with cancer is centralized at the Children's Hospital. After treatment, all are followed up by the same center for at least five years or until they are 18 years old. Later they are followed up regularly at the outpatient Clinic for Late Effects at the Institute of Oncology, Ljubljana. This policy has been in effect since 1986 (2). The patients enrolled in our studies are seen at least once every year for evaluation of their somatic and social status. In most of them their psychoemotional status is also evaluated.

Between 1959 and 2006, 1984 children with cancer were registered at the Cancer Registry in Slovenia. Of the 102 who developed one or more SM, 27 died. The remaining 75 patients with SM, 35 women and 40 men, have been followed up regularly. For the present study, they were matched with 75 cancer survivors who did not develop SM (control group). Matching was done by stratifying the register population by year at diagnosis of the first malignancy, and by sex, age, and diagnosis and treatment of the first cancer. From each stratum, individuals were selected randomly. The age at diagnosis of the first malignancy of both groups ranged from 0 to 16 years, with a mean age of 8.4 (standard deviation, $\mathrm{SD}=5.1$ ) years for survivors with SM as well as for controls. The mean age at last evaluation (December 2009) was $34.9(\mathrm{SD}=8.7)$ years for survivors with $\mathrm{SM}$ and $33.9(\mathrm{SD}=7.7)$ years for controls. The diagnosis of the 1st malignancy in survivors with SM and their controls was leukemia in $25.3 \%$, Hodgkin disease (HD; 
Table 1 Development of second malignancy in 75 survivors

\begin{tabular}{|c|c|c|}
\hline Diagnosis of first malignancy, $\mathrm{n}(\%)$ & & Diagnosis of second malignancy, $\mathrm{n}$ \\
\hline Leukemia & $19(25.3)$ & $\begin{array}{l}\text { Other Carcinomas 4, Brain 3, NHL 3, HD 2, Malignant bone tumors 2, } \\
\text { Testis 2, Soft-Tissue Sarcomas 1, Thyroid Carcinoma 1, Leukemia 1, }\end{array}$ \\
\hline Brain & $11(14.7)$ & Brain 7, Thyroid Carcinoma 2, Other Carcinomas 2 \\
\hline HD & $15(20.0)$ & Thyroid Carcinoma 9, Other Carcinomas 5, Malignant melanoma 1 \\
\hline NHL & $5(6.7)$ & Other Carcinomas 3, Brain 1, Thyroid Carcinoma 1 \\
\hline Renal tumors & $3(4.0)$ & Thyroid Carcinoma 2, Brain 1 \\
\hline Neuroblastoma & $4(5.3)$ & Thyroid Carcinoma 2, Rhabdomyosarcoma 1, Other Carcinomas 1 \\
\hline $\begin{array}{l}\text { Soft-Tissue Sarcomas / } \\
\text { Rhabdomyosarcoma }\end{array}$ & $5(6.7)$ & Other Carcinomas 4, Soft-Tissue Sarcomas 1 \\
\hline $\begin{array}{l}\text { Malignant bone tumors / Ewing's } \\
\text { \& PNET }\end{array}$ & $5(6.7)$ & Malignant bone tumors 2, Other Carcinomas 2, Leukemia 1 \\
\hline Gonads & $3(4.0)$ & Soft-Tissue Sarcomas 1, Ovary 1, Other Carcinomas 1 \\
\hline Thyroid Carcinoma & $1(1.3)$ & Soft-Tissue Sarcomas 1 \\
\hline Other Carcinomas & $2(2.7)$ & Thyroid Carcinoma 1, Other Carcinomas 1 \\
\hline Retinoblastoma & $1(1.3)$ & Soft-Tissue Sarcomas 1 \\
\hline Unspecified malignant neoplasms & $1(1.3)$ & Thyroid Carcinoma 1 \\
\hline
\end{tabular}

$\mathrm{HD}=$ Hodgkin's disease; $\mathrm{NHL}=$ non-Hodgkin's lymphoma; PNET = primitive neuroectodermal tumor

$20 \%)$, brain tumors (14.7\%), non-Hodgkin lymphoma (NHL; 6.7\%) and remaining conditions (33.3\%). The great majority of patients were treated with both irradiation and chemotherapy (49.3\%), others had surgery and irradiation (15.3\%) or surgery and chemotherapy (10.7\%), $13.3 \%$ of patients were treated with all three methods, and a few had only one (11.3\%). All 150 survivors were assessed five or more years after treatment. The SM in the 75 survivors are presented in detail in Table 1. The most common SM were other carcinomas $(23 ; 30.7 \%)$, thyroid carcinomas $(19 ; 25.3 \%)$ and brain tumors $(12 ; 16.0 \%)$, which developed in irradiated areas. Five soft tissue tumors (6.7\%) and miscellaneous other types accounted for the rest. The third tumors were either carcinomas (8) or brain tumors (4), all in irradiated areas.

The study was performed after approval by our Human Investigations Committee and in accordance with the precepts of the Helsinki Declaration. Informed consent was obtained from each participant in the study and it was concluded in December 2009.

\section{Measurements}

\section{Evaluation of socioeconomic status}

Survivors included in this study had previously been evaluated and analyzed as to their late somatic sequelae including: neurological deficits (16), endocrine deficits (17), renal function (18), cardiac status (19), SM (20), and psychosocial status (21). For the present study, the group of survivors with $\mathrm{SM}$ and the control group were compared as to their living environment, education, employment, marital status, and, in the 35 women, childbearing. Living environment was listed as city, town or countryside, following official Slovene definitions according to the number of inhabitants $(>100000$, 3000-100000, and <3000 inhabitants, respectively). The influence of rural versus urban environment might become impor- 
tant for the survivors in their future life. In the city, opportunities for schooling and education are better than in our countryside where, in contrast, marital status may assume more importance.

\section{Psychological evaluation}

The psychological status was evaluated in the second part of our study. It was performed on a voluntary basis; not all patients responded to our invitation. Twenty-nine of the 75 with SM had had psychological evaluation after the diagnosis of the first malignancy; they were invited to participate in a follow-up psychological assessment and 17 responded. In them, the first psychological evaluation had been performed 9 to 32 years before (mean $=15.9, S D=5.2)$. The survivors without $\mathrm{SM}$ were tested 7 to 28 years (mean=15.2, $\mathrm{SD}=5.3$ ) after the diagnosis of the first cancer. The mean elapsed time between the first and the second psychological tests for those with $\mathrm{SM}$ was $12.7(\mathrm{SD}=4.5)$ years, with a minimum of 5 years and maximum of 22 years.

Seven men and 10 women with SM, and their controls were evaluated. To be able to compare results, the same tests were employed as those used several years before. These were the standard Bender visual motor gestalt test $(22,23)$ for evaluating visualmotor functioning and visual perception skills, the Rorschach test (24) for personality characteristics and emotional functioning, and the Wechsler Bellevue test (25) for intelligence. The presence and the degree of any psychoorganic syndrome or emotional disorder, if present, was determined on the basis of the qualitative evaluation of the results of all three instruments. The term psychoorganic syndrome in this context includes disturbance of concentration, memory, learning processing or intellectual efficiency. Emotional disorder here includes emotional instability, dullness and a lower ability to adapt to changing circumstances. Both psychological characteristics were classified by the same expert into four categories: 0 - no disorder; 1 - disorder present; 2 - significant disorder; and 3 - very significant disorder. From our results we determined whether a disturbance was present in an individual and, if so, its severity. These semi-objective results, however, had to be evaluated subjectively as well since they are not amenable to mathematical analyses.

Following the hypothesis that the diagnosis of SM could affect emotional functioning, either in increasing anxiety, or deepening depression, the Plutchik Profile Index Emotions (26) was used at our second examination in the 17 patients with SM. Their results were compared with the norms valid for the general population of Slovenia (27).

\section{Statistical analysis}

Numerical data are presented as mean and SD and categorical data as proportions. To assess the difference between the observed and expected frequencies for categorical variables, the Pearson's chi-squared test, Fisher's exact test or Freeman-Halton extension of the Fisher's exact test was applied, as appropriate. In order to compare the psychological status and the type of tumor, the psychoorganic syndrome and emotional disorder variables were defined as "no disorder" and "disorder" present, while the diagnosis of the first malignancy was categorized as "brain tumor" and "other tumor". A $p$ value of $<0.05$ was considered significant. Data were analyzed using the PASW 18 software (SPSS Inc., Chicago, IL, USA).

\section{Results}

\section{Evaluation of socioeconomic status}

There was no difference in the environment where the patients with SM or the controls were living $\left(\chi_{(2)}^{2}=0.33, \mathrm{p}=0.863\right)$ nor in the 
Table 2 Social status in SM and control group

\begin{tabular}{|c|c|c|c|c|c|c|c|}
\hline \multirow[b]{2}{*}{ Variable } & \multicolumn{3}{|c|}{ SM } & \multicolumn{3}{|c|}{ Control } & \multirow[b]{2}{*}{$P^{*}$} \\
\hline & $\begin{array}{l}\text { Male } \\
n=40\end{array}$ & $\begin{array}{l}\text { Female } \\
\mathrm{n}=35\end{array}$ & $\begin{array}{l}\text { All } \\
n=75\end{array}$ & $\begin{array}{l}\text { Male } \\
\mathrm{n}=40\end{array}$ & $\begin{array}{l}\text { Female } \\
\mathrm{n}=35\end{array}$ & $\begin{array}{l}\text { All } \\
n=75\end{array}$ & \\
\hline Residence, n (\%) & & & & & & & 0.863 \\
\hline City & 7 & 2 & $9(12.0)$ & 7 & 0 & $7(9.3)$ & \\
\hline Town & 10 & 13 & $23(30.7)$ & 13 & 12 & $25(33.3)$ & \\
\hline Country & 23 & 20 & $43(57.3)$ & 20 & 23 & $43(57.3)$ & \\
\hline Marital status, n (\%) & & & & & & & 0.839 \\
\hline Married / living with partner & 9 & 12 & $21(28.0)$ & 7 & 12 & $19(25.3)$ & \\
\hline Single / living with parents & 30 & 20 & $50(66.7)$ & 33 & 20 & $53(70.7)$ & \\
\hline Living alone & 1 & 3 & $4(5.3)$ & 0 & 3 & $3(4.0)$ & \\
\hline $\begin{array}{l}\text { Education, } \mathrm{n}(\%) \\
\text { (12 have not completed schooling) }\end{array}$ & & & & & & & 0.300 \\
\hline Grammar & 7 & 8 & $15(20.0)$ & 5 & 2 & $7(9.3)$ & \\
\hline Vocational & 10 & 7 & $17(22.7)$ & 12 & 7 & $19(25.3)$ & \\
\hline High & 12 & 10 & $22(29.3)$ & 11 & 9 & $20(26.7)$ & \\
\hline College & 3 & 3 & $6(8.0)$ & 2 & 3 & $5(6.7)$ & \\
\hline University & 8 & 6 & $14(18.7)$ & 8 & 12 & $20(26.7)$ & \\
\hline Auxiliary & 0 & 1 & $1(1.3)$ & 2 & 2 & $4(5.3)$ & \\
\hline $\begin{array}{l}\text { Employed, } \mathrm{n}(\%) \\
\text { (138 with completed schooling) }\end{array}$ & & & & & & & 0.818 \\
\hline In their profession & 21 & 20 & $41(59.4)$ & 19 & 22 & $41(59.4)$ & \\
\hline Other & 6 & 3 & $9(13.0)$ & 9 & 3 & $12(17.4)$ & \\
\hline Unemployed & 5 & 5 & $10(14.5)$ & 3 & 4 & $7(10.1)$ & \\
\hline Retired / social support & 3 & 6 & $9(13.0)$ & 4 & 5 & $9(13.0)$ & \\
\hline Children, n (\%)† & & & & & & & 0.947 \\
\hline 0 & 32 & 20 & $52(69.3)$ & 33 & 19 & $52(69.3)$ & \\
\hline 1 & 5 & 6 & $11(14.7)$ & 3 & 9 & $12(16.0)$ & \\
\hline 2 & 2 & 8 & $10(13.3)$ & 3 & 5 & $8(10.7)$ & \\
\hline 3 & 1 & 0 & $1(1.3)$ & 0 & 2 & $2(2.7)$ & \\
\hline
\end{tabular}

$\mathrm{SM}=$ secondary malignancy; ${ }^{*}$ Comparison of social status variables with regard to patient group. t One answer is missing from a female patient (SM group) and another from a male patient (control group).

marital status of the two groups $(\mathrm{p}=0.839)$ (Table 2).

Most patients in both groups were still single and living with parents $(67 \%$ and $71 \%)$. About one quarter of both groups were married or living with a partner. Although there were some differences between the SM and control group for particular levels of education, these did not attain statis- tical significance $(\mathrm{p}=0.300)$. The employment status of the 2 groups was comparable $(\mathrm{p}=0.818)$. Most (around 60\%) were working. In each group there were eight who had retired (for disability) because of severe adverse sequelae after treatment for either the first or subsequent cancer(s). Five of the 8 retired survivors with SM had had a primary brain tumor. Another had a bone tumor 
with amputation and later a disarticulation for a secondary tumor and a pneumonectomy for metastastic disease. Two had HD with severe sequelae after radiation therapy (RT) to the mediastinum (one also had a secondary breast cancer).

Three of the 8 retired subjects in the control group had a primary brain tumor; one with Ewing's sarcoma had severe sequelae after chemotherapy (ChT) and 50 Gy RT to the pelvis. Another had hypertension and epilepsy after surgery and ChT for a malignant tumor of the suprarenal gland, and three others had pulmonary fibrosis and heart failure after RT to the mediastinum for HD.

One survivor in each group receives the social support, being disabled after treatment of a primary brain tumor. Comparison of the study groups according to the number of children born, showed very similar proportions ( $\mathrm{p}=0.947)$. Most (69\%) were childless: 32 men with SM and 33 in the control group, as were 21 women with SM and 19 in the control group.

The proportion of women who gave birth of the general population of women in Slo- venia in the year 2002 was $75.2 \%$ (27). The childhood cancer survivors in both groups gave birth in significantly lower proportions than the general Slovene population: $40.0 \%$ for the SMs, and $45.7 \%$ for the controls $(\mathrm{p}<0.0001)$. Furthermore, $40.6 \%$ of Slovene women had 2 children in 2002. This is a significantly higher proportion than that of the SM women $(22.9 \%, \mathrm{p}=0.033)$ or those of the control group $(14.3 \%, \mathrm{p}=0.002)$ (Figure 1).

Twenty-two of 150 childhood cancer survivors (14.7\%) had brain tumors and 128 (85.3\%) had other diagnoses. Comparison of socioeconomic status and the presence of a brain tumor (brain/other tumors) showed statistically significant relationships with education $(\mathrm{p}<0.001)$ and employment $\left(\chi^{2}=15.52, \mathrm{p}<0.001\right)$. About 2 of 3 nonbrain-tumor patients finished high school, college or university studies $(83 / 128,64.8 \%)$, while perhaps only one in five of those with a brain tumor attained comparable educational levels $(4 / 22,18.2 \%)$. With regard to employment, only $8 / 21$ (38.1\%) patients with a brain tumor were employed, contrasted with $76 / 117$ (65.0\%) of those with

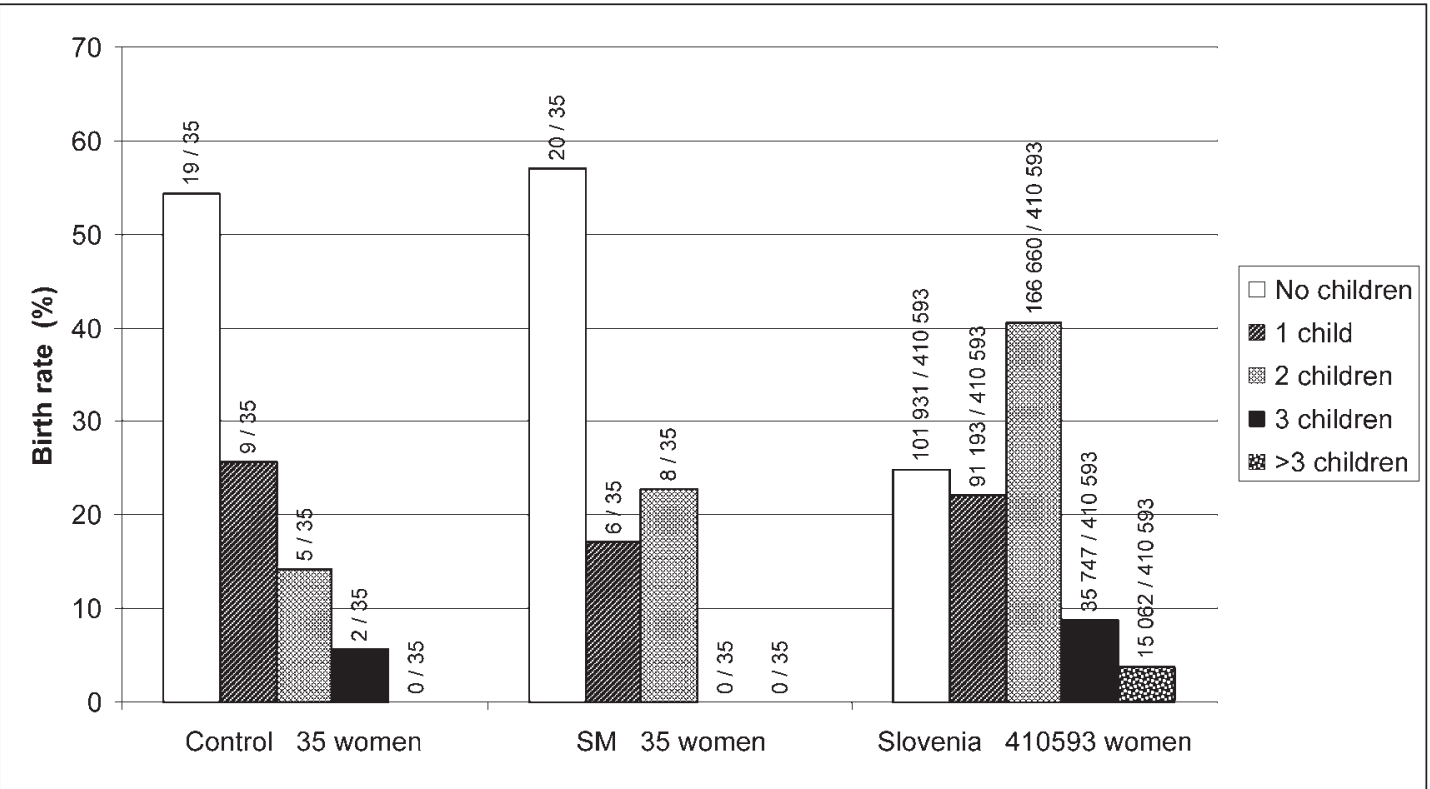

$\mathrm{SM}=$ Secondary malignancy.

Figure 1 Women 22-49 years old, birth rate 
some other malignancy. The unemployed or retirement rate was 13/21 (61.9\%) for brain tumor subjects, and 18/117 (15.4\%) for those with other primary diagnoses.

\section{Psychological evaluation}

The results of psychological evaluation of the 17 childhood cancer survivors with SM and 17 controls are shown in Table 3.

There was no significant difference in the frequency or severity of the psychoorganic syndrome or emotional disorder rankings between the SM group at the second evaluation and the control group ( $\mathrm{p}=0.382$ and $\mathrm{p}=0.265$, respectively). Table 3 shows that there was no significant difference, within the cognitive and emotional spheres, between the two groups. This table also shows that there are no differences within the group of individuals with SM at the first as compared to the second examination. Disturbances of concentration and attention, shortening of attention span and weakness of memory were already present at the first evaluation, and visual-motoric incoordination was also observed. Notably, however, intellectual functioning (with the excep- tion of one woman) was at least in the mean range, possibly even above it.

The second psychological evaluation of psychoorganic syndromes and the emotional sphere did not show any significant differences as compared to the results of the first ( $\mathrm{p}=1$ and $\mathrm{p}=0.999$, respectively). Early changes were observed in 13 subjects; they included some personal characteristics, interpreted as aggravated anxiety and a diminished capacity for normal aggressiveness and assertiveness. Comparison of psychological status (no disorder/disorder) and the presence of a brain tumor (brain/other tumors) showed significantly more instances of the psychoorganic syndrome in patients with brain tumors as the first malignancy than in those with other tumors (4/4 versus $10 / 30$ ( $\mathrm{p}=0.022$ ), respectively). However, no such clear relationship was found when the SM was a brain tumor ; i.e., 3/5 patients with a brain tumor and psychoorganic syndrome versus $3 / 12$ with some other secondary tumor $(p=0.280)$. For emotional disorders, there was no evidence of any relationship with the type of tumor: $3 / 4$ versus $24 / 30$ patients for the first malignancy $(\mathrm{p}=1)$. The proportion of psychoorganic syndrome was

Table 3 Psychological evaluation at diagnosis of first and of second malignancy

\begin{tabular}{|c|c|c|c|c|c|}
\hline \multirow{2}{*}{ Psychological disorder } & \multicolumn{2}{|l|}{$\operatorname{SM}(n=17)$} & \multirow{2}{*}{$\begin{array}{l}\text { Control } \\
(n=17)\end{array}$} & \multirow{2}{*}{$\begin{array}{l}\mathrm{P} \\
1^{\text {st }} \mathrm{Dg} / 2^{\text {nd }} \mathrm{Dg}\end{array}$} & \multirow{2}{*}{$\begin{array}{l}\mathrm{P} \\
2^{\text {nd }} \mathrm{Dg} / \text { control }\end{array}$} \\
\hline & At $1^{\text {st }} \mathrm{Dg}$ & At $2^{\text {nd }} \mathrm{Dg}$ & & & \\
\hline Psychoorganic syndrome, n (\%) & & & & 1 & 0.382 \\
\hline 0 & $11(64.7)$ & $11(64.7)$ & $9(52.9)$ & & \\
\hline 1 & $2(11.8)$ & $2(11.8)$ & $3(17.6)$ & & \\
\hline 2 & $3(17.6)$ & $3(17.6)$ & $1(5.9)$ & & \\
\hline 3 & $1(5.9)$ & $1(5.9)$ & $4(23.5)$ & & \\
\hline Emotional disorder, n (\%) & & & & 0.999 & 0.265 \\
\hline 0 & $2(11.8)$ & $1(5.9)$ & $5(29.4)$ & & \\
\hline 1 & $11(64.7)$ & $11(64.7)$ & $8(47.1)$ & & \\
\hline 2 & $4(23.5)$ & $5(29.4)$ & $4(23.5)$ & & \\
\hline 3 & 0 & 0 & 0 & & \\
\hline
\end{tabular}

$\mathrm{Dg}=$ diagnosis; $\mathrm{SM}=$ secondary malignancy; 0 = no disorder; 1 = disorder present 2 = significant disorder; 3 = very significant disorder 


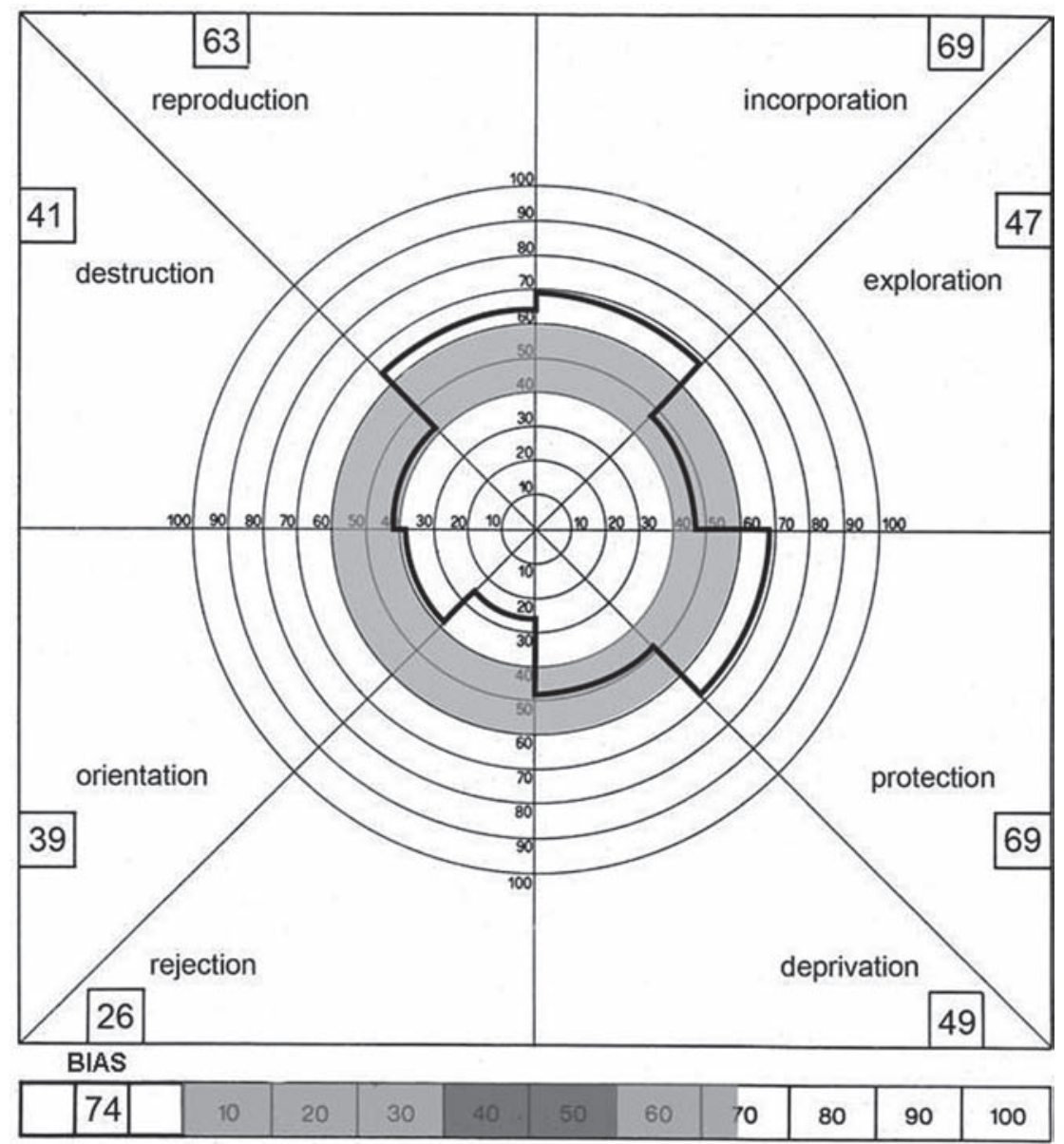

Figure 2 Plutchik Profile Index Emotions in survivors with SM. Scores for 8 emotional dimensions are presented in percentiles. Grey areas represent normal values (range 40-60). Average scores for emotional dimensions are shown in frames in each of 8 fields and illustrated with a bold black line.

$4 / 5$ versus $12 / 12(\mathrm{p}=0.294)$ for the SM patients with brain tumors versus those with other tumors, respectively.

The result of the Plutchik Profile Index Emotions instrument was used in SM patients at their second psychological examination, in an attempt to find out how these individuals function on average. The results are shown in Figure 2.

Units 0 to 100 are percentile. Average scores of particular emotional dimensions are transformed, with the help of testing tables, into percentile scores. Values 40 to 60 are normal. The grey areas represent normal values, the uninterrupted black line shows the mean value of the 17 evaluated patients with SM, and the individual values are very close to each other. This profile suggests that these 17 survivors with SM see themselves as socially adjusted with only a few of them markedly inverted, isolated or distrustful (Reproduction and Incorporation) perhaps along with some diminished elasticity and adaptability to new circumstances, as indicated by the next characteristic Protection. This is elevated, suggesting a fear of not being able to deal with future difficulties. The low average for the dimension Rejection also 
corroborates this point of view, indicating that those tested were probably less decisive and less self-sufficient than the general population. They might lack fighting spirit and enterpreneurship. This, in turn, is corroborated by the next two personality dimensions: Orientation and Destruction. The first one suggests a marginally lower capacity of planning for the future due to a perceived lack of self-control. The second dimension emanates from the first one, namely, a certain lack of healthy aggressiveness and lifeenhancement. Scores for the 17 were at the lower average levels. Notably, such individuals do not feel particularly sad or depressed, and have, on average, no more sense of being marginalized, deprived or lonely than the general population (Deprivation). They try to adjust to new circumstances just as those without their experience (Exploration). The elevated values on the dimension Bias suggest that they are trying to show themselves in the best possible light.

\section{Discussion}

Impaired quality of life for childhood cancer survivors has been reported $(28,29)$. We hypothesized that the advent of SM in them would exacerbate or worsen pre-existing psychosocial difficulties, but this did not prove to be the case.

Our research encompassed several QOL indices. One of these was employment status. The same proportion of SM subjects and their controls were working or had undergone early retirement because of severe disabilities related to treatment of the first or SM. These characteristics resulted in diminished competitiveness and impaired capacity for personal contacts. They were pronounced in four of the 13 , and prevented ordinary socializing with their peers; these four were still living with their parents.

The birth rate is another QOL measure, and we found no detectable difference in childbearing among those with SM and their controls. Somatic dysfunctions did not fully explain the fact that few children were born in either study population. Other reasons, such as socioeconomic and emotional, must be invoked to explain the findings (29). It is of interest, however, that childhood cancer survivors with SM had no more than two children, whereas in the control group there were some women with three (Figure 1). For all 305 female childhood cancer survivors in Slovenia (out of 1984 registered children with cancer between years 1959 and 2006), the proportion that was childless was significantly higher than in the general population ( 68.5 vs. $24.8 \%, \mathrm{p}<0.0001)$. There may be somatic reasons why childhood cancer survivors remain childless. For example, we found hypogonadism in 35, and sterility in 9 of our long term survivors. Even when those 44 women were excluded, the birth rate was still low (165/261, 63.2\%).

We did not find any marked differences in psychological deviations between the 17 survivors with SM and their controls; neither did the second psychological evaluation of the emotional sphere show any marked differences as compared to the results of the first evaluation. The results of the Plutchik Profile Index Emotions, used only in those with SM, showed that they feel, on an emotional footing, equal to the general population. This suggests that those who cope with the primary malignancy can successfully avoid later psychoorganic or emotional disturbances. It is noteworthy that they do not tend to be sad or depressed or have any sense of emotional, social, or material deprivation. This may be indicative of a strong innate defense against any anxiety that might be caused by either the primary cancer or SM. That inner strength could lead to unwarranted optimism that, however, should not be discouraged in our opinion. It is considered by us to be of great help in lives marred by uncertainties. 
The group of patients with SM, who were psychologically evaluated twice, is small, numbering but 17 , which might be a significant limitation to this study. Such study populations are rare, however, and worthy of record. The uniformity of the results among them tends to be convincing as is the comparison of the 75 SM survivors with their control group. It might be expected that this report will encourage studies on larger patient populations.

Adding to the credibility and interest of the data reported here is the unusually long follow-up time plus the fact that the same psychologist and oncologist evaluated the psychological and socioeconomic functioning of the patients (30). This continuity is favored by our system of smoothly shifting patients from the pediatric to the adult follow up clinic $(31,32)$.

A limitation of our study is the absence of an independent validation of the classification of psychoorganic syndromes and emotional disorders.

Circumstances contributing to our results might be our system of rehabilitation in groups, promoting social interaction and mutual help. We have established the Foundation »The Little Knights« supporting survivors of childhood cancer (33). This takes care of some of their needs, both material and psychological. As a result of our positive experience with this work it might be recommended as a model to help childhood cancer survivors.

\section{Conclusions}

There seems to be no difference in the educational level or the marital or employment status between survivors of childhood cancer who do or do not develop SM. When compared with the number of children born to the general population of women in Slovenia, childhood cancer female survivors in both groups have significantly fewer children. The second psychological evaluation in the emotional sphere of the childhood cancer survivors with SM showed no marked differences from the results of their first tests performed years before. Subjects with SM do not feel particularly sad or depressed, and have, on the average, no more sense of being marginalized, deprived or lonely than the general population. They try to adjust to new circumstances just as those without their experience, and try to show themselves in the best possible light.

\section{Addendum}

\section{An illustrative case}

Statistical data are important, but personal observations are of value, too. A young women had this to say about herself at one of our group sessions: "I was always very shy as a child, but my self-confidence grew when I first fell ill. I found I could confront my first cancer --- Hodgkin's disease --- and all that went with that diagnosis. I could discuss matters with the doctors, family, friends and other patients in the clinic. When I was 28 and developed signs of my secondary cancer, I had to do things by myself. My self-confidence then proved to be important because my family physician did not take my concerns seriously. He sent me to a psychiatrist. I decided not to listen to him and went instead to the Late Effects Clinic at the Oncology Institute. They made the diagnosis and treated me." Her secondary malignancy was breast cancer, and she has now been disease-free for 12 years.

\section{Acknowledgement}

Many thanks to Giulio D’Angio for his generous assistance with the manuscript.

Supported by: Ministry of Higher Education, Science and Technology RS (Grant No.: L3-396)

Conflict of interest

The authors declare that they have no conflict of interest. 


\section{Authors' contributions:}

Conception and design: BJ; Acquisition, analysis and interpretation of data: RK and MČS; Drafting the article: RK and MČS; Critical revision for important intellectual content: GD’A.

\section{References}

1. Oeffinger KC, Mertens AC, Sklar CA, Kawashima T, Hudson MM, Meadows AT, et al. (Childhood Cancer Survivor Study). Chronic health conditions in adult survivors of childhood cancer. N Engl J Med. 2006;355(15):1572-82.

2. Jereb B. Model for long-term follow-up of survivors of childhood cancer. Med Pediatr Oncol. 2000;34:256-8.

3. Skinner R, Wallace WH, Levitt GA. Long-term follow-up of people who have survived cancer during childhood. Lancet Oncol. 2006;7:489-48.

4. Frobisher C, Lancashire ER, Winter DL, Stevens MCG, Hawkins MM; British Childhood Cancer Survivor Study. Long-term population-based divorce rates among adult survivors of childhood cancer in Britain. Pediatr Blood Cancer. 2010;54:116-22.

5. Friderick PL, Rochelle Stone BS. Survivors of Cancer Childhood. Ann Intern Med. 1976;84:551-3.

6. Svetičič J, Marušič A, Jereb B. Are among childhood cancer survivors depression and suicidal behavour more frequent? Onkologija. 2006;10:75-80.

7. Recklitis CJ, Lockwood RA, Rothwell MA, Diller LR. Suicidal ideation and attempts in adult survivors of childhood cancer. J Clin Oncol. 2006;24: 3852-7.

8. Schulte F, Barrera M. Social competence in childhood brain tumor survivors: a comprehensive review. Support Care Cancer. 2010;18:1499-513.

9. O'Leary TE, Diller L, Recklitis CJ. The effects of response bias on self-reported quality of life among childhood cancer survivors. Qual Life Res. 2007;16:1211-20.

10. Taylor N, Absolom K, Michel G, Urguhart T, Gerrard M, Jenkins A, et al. Comparison of selfreported late effects with medical records among survivors of childhood cancer. Eur J Cancer. 2010;46:1069-78.

11. McDougall J, Tsonis M. Quality of life in survivors of childhood cancer: a systematic review of the literature (2001-2008). Support Care Cancer. 2009;17:1231-46.

12. Sundberg KK, Doukkali E, Lampic C, Eriksson LE, Arvidson J, Wettergren L Long-term survivors of childhood cancer report quality of life and health status in parity with a comparison group. Pediatr Blood Cancer. 2010;55:337-43.

13. Zeltzer LK, Recklitis C, Buchbinder D, Zebrack B, Casillas J, Tsao JC, et al. Psychological status in childhood cancer survivors: a report from the Childhood Cancer Survivor Study. J Clin Oncol. 2009;27:2396-404.

14. Meyers CA, Perry JR Cognition and Cancer. Cambridge University press, Cambridge, UK; 2008.

15. Jereb B, Korenjak R, Kržišnik C, Petrič-Grabnar G, Zadravec-Zaletel L, Anžič J, et al. Late sequelae in children treated for brain tumors and leukemia. Acta Oncol. 1994;33:159-64.

16. Macedoni-Lukšič M, Jereb B, Todorovski L. Longterm sequelae in children treated for brain tumors: impairments, disability, and handicap. Pediatr Hematol Oncol. 2003;20:89-101.

17. Zadravec-Zaletel L, Bratanič N, Jereb B. Gonadal function in patients treated for leukemia in childhood. Leuk Lymphoma. 2004;45:1797-802.

18. Kveder R, Jereb B, Dremelj M. Late consequences on renal function in long term childhood cancer survivors. Pediatric Blood \& Cancer. 2006;47:495-6.

19. Velenšek V, Mazić U, Kržišnik C, Demšar D, Jazbec J, Jereb B. Cardiac damage after treatment of childhood cancer: a long-term follow-up. BMC Cancer. 2008;8:141.

20. Jazbec J, Todorovski L, Jereb B. Classification tree analysis of second neoplasms in survivors of childhood cancer. BMC Cancer. 2007;7:1-6.

21. Bürger-Lazar M, Jereb B. Personality of childhood cancer survivors. Med Pediatr Oncol. 2000;35:316.

22. Bender L.A. visual motor gestalt test and its clinical use. American Orthopsychiatric Association, Research Monographs (No. 3), New York; 1938.

23. Bender L. Instructions for the use of the VisualMotor Gestalt Test. American Orthopsychiatric Association, New York; 1946.

24. Exner JE, Erdberg P. The Rorschach-A Comprehensive System, Volume 2, Advanced Interpretation, 3rd edn. Wiley, New York; 2005.

25. Wechsler D. The Measurement of Adult Intelligence. Williams \& Witkins, Baltimore, MD; 1939.

26. Plutchik R. The circumplex as a general model of the structure of emotions and personality. In: Plutchik R, Conte HR (eds). Circumplex models of personality and emotions. American Psychological Association, Washington DC; 1997. p. 17-45.

27. Statistical Office of the Republic of Slovenia [Internet]. Available from: http://www.stat.si/eng/ index.asp

28. Lancashire ER, Frobisher C, Reulen RC, Winter DL, Glaser A, Hawkins MM. . Educational attainment among adult survivors of childhood cancer 
in Great Britain: a population-based cohort study. J Natl Cancer Inst. 2010;102:254-70.

29. Green DM, Zevon MA, Hall B. Achievement of life goals by adult survivors of modern treatment of childhood cancer. Cancer. 1991;67:206-13.

30. Robison LL, Green DM, Hudson M, Meadows AT, Mertens AC, Packer RJ, et al. Long-term outcomes of adult survivors of childhood cancer. Cancer. 2005;104(Suppl 11):S2557-64.
31. Henderson TO, Friedman DL, Meadows AT. Childhood cancer survivors: transition to adult-focused risk-based care. Pediatrics. 2010;126:129-36.

32. von der Weid NX. Adult life after surviving lymphoma in childhood. Support Care Cancer. 2008;16:339-45.

33. Jereb B. The little knights. [S. 1.: s. n., 200-] 2004. 